BMC

Microbiology

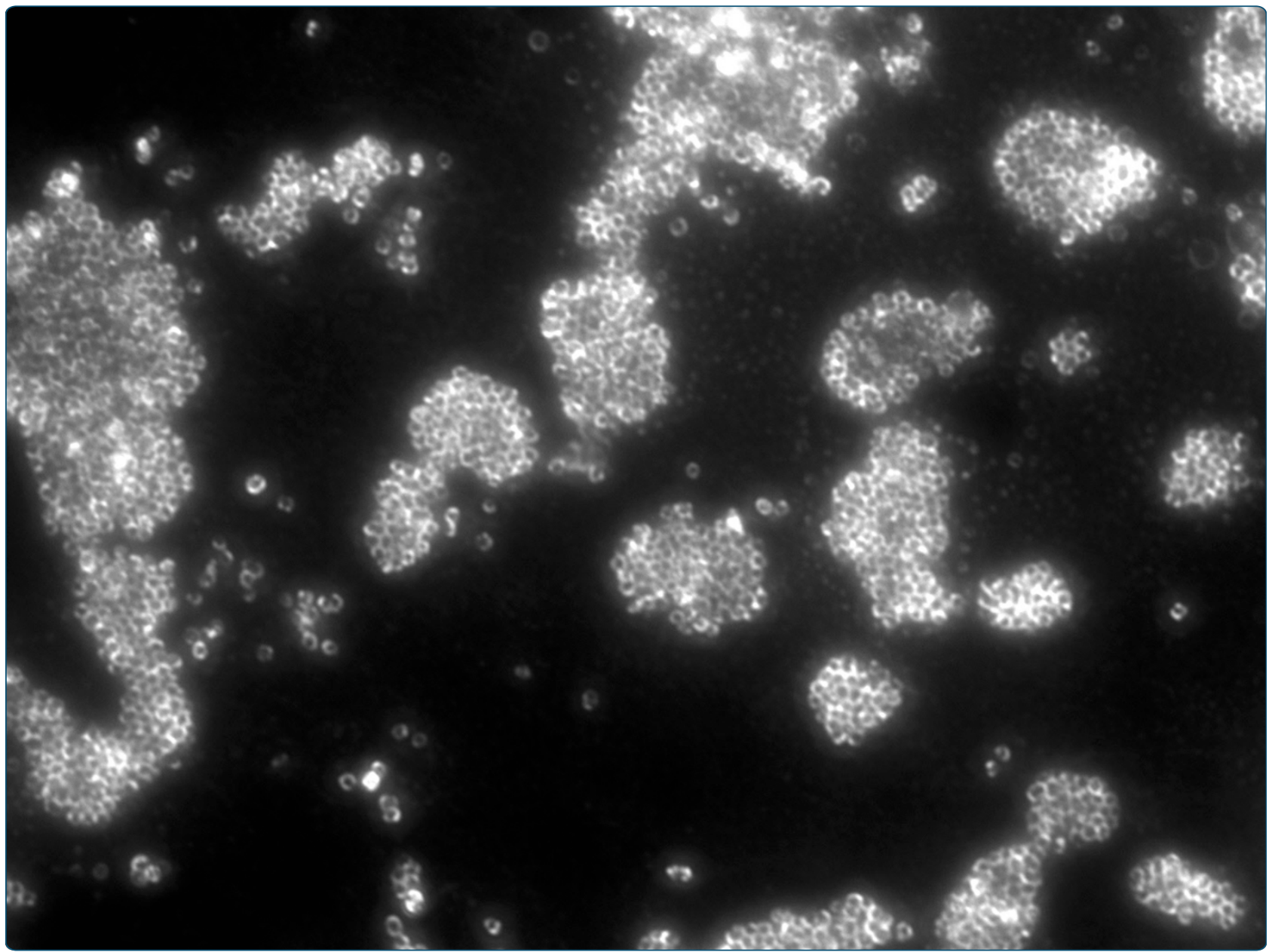

An extracellular Staphylococcus epidermidis polysaccharide: relation to Polysaccharide Intercellular Adhesin and its implication in phagocytosis

Spiliopoulou et al.

() Biomed Central 


\title{
An extracellular Staphylococcus epidermidis polysaccharide: relation to Polysaccharide Intercellular Adhesin and its implication in phagocytosis
}

Anastasia I Spiliopoulou 1,2, Maria I Krevvata', Fevronia Kolonitsiou', Llinos G Harris², Thomas S Wilkinson², Angharad P Davies ${ }^{2}$, Georgios O Dimitracopoulos ${ }^{1}$, Nikos K Karamanos ${ }^{3}$, Dietrich Mack ${ }^{2^{*}}$ and Evangelos D Anastassiou ${ }^{1 *}$

\begin{abstract}
Background: The skin commensal and opportunistic pathogen Staphylococcus epidermidis is a leading cause of hospital-acquired and biomaterial-associated infections. The polysaccharide intercellular adhesin (PIA), a homoglycan composed of $\beta-1,6$-linked $\mathrm{N}$-acetylglucosamine residues, synthesized by enzymes encoded in icaADBC is a major functional factor in biofilm accumulation, promoting virulence in experimental biomaterial-associated S. epidermidis infection. Extracellular mucous layer extracts of $S$. epidermidis contain another major polysaccharide, referred to as 20-kDa polysaccharide (20-kDaPS), composed mainly out of glucose, N-acetylglucosamine, and being partially sulfated. 20-kDaPS antiserum prevents adhesion of S. epidermidis on endothelial cells and development of experimental keratitis in rabbits. Here we provide experimental evidence that 20-kDaPS and PIA represent distinct molecules and that 20-kDaPS is implicated in endocytosis of S. epidermidis bacterial cells by human monocyte-derived macrophages.
\end{abstract}

Results: Analysis of 75 clinical coagulase-negative staphylococci from blood-cultures and central venous catheter tips indicated that 20-kDaPS is expressed exclusively in S. epidermidis but not in other coagulase-negative staphylococcal species. Tn917-insertion in various locations in icaADBC in mutants M10, M22, M23, and M24 of S. epidermidis 1457 are abolished for PIA synthesis, while 20-kDaPS expression appears unaltered as compared to wild-type strains using specific anti-PIA and anti-20-kDaPS antisera. While periodate oxidation and dispersin B treatments abolish immuno-reactivity and intercellular adhesive properties of PIA, no abrogative activity is exerted towards 20-kDaPS immunochemical reactivity following these treatments. PIA polysaccharide I-containing fractions eluting from Q-Sepharose were devoid of detectable 20-kDaPS using specific ELISA. Preincubation of non-20-kDaPS-producing clinical strain with increasing amounts of 20-kDaPS inhibits endocytosis by human macrophages, whereas, preincubation of 20-kDaPS-producing strain ATCC35983 with 20-kDaPS antiserum enhances bacterial endocytosis by human macrophages.

Conclusions: In conclusion, icaADBC is not involved in 20-kDaPS synthesis, while the chemical and chromatographic properties of PIA and 20-kDaPS are distinct. 20-kDaPS exhibits anti-phagocytic properties, whereas, 20-kDaPS antiserum may have a beneficial effect on combating infection by 20-kDaPS-producing S. epidermidis.

\footnotetext{
* Correspondence: D.Mack@swansea.ac.uk; edanastassiou@med.upatras.gr

'Department of Microbiology, School of Medicine, University of Patras, Patras, Greece

${ }^{2}$ Medical Microbiology and Infectious Diseases, Institute of Life Science, The

College of Medicine, Swansea University, Swansea, UK

Full list of author information is available at the end of the article
} 


\section{Background}

Staphylococcus epidermidis and other coagulase-negative staphylococci (CoNS) constitute the most frequent causes of hospital-acquired infections and are often associated with the use of medical devices [1]. Virulence is mainly attributed to surface colonization and biofilm formation [2]. A biofilm represents an adherent, structured, high density community of bacterial cells [3] embedded in an extracellular matrix, previously called slime. Polysaccharide Intercellular Adhesin (PIA), a homoglycan composed of $\beta$-1,6-linked 2-deoxy-2-amino-D-glucopyranosyl residues, is considered to be the major functional component mediating intercellular adhesion in S. epidermidis biofilms [4-7]. Biofilm formation mediated by PIA is a major virulence factor in experimental biomaterialassociated infection [8] and provides also protection against opsonophagocytosis and activity of anti-microbial peptides $[9,10]$. The genes encoding PIA production are organized in the icaADBC operon [11-13].

Moreover, a polysaccharide molecule with $20-\mathrm{kDa}$ average molecular mass, defined as $20-\mathrm{kDaPS}$, was isolated from S. epidermidis ATCC35983 (RP12), ATCC35984 (RP62A) and clinical biofilm-producing strains by ionexchange chromatography and gel filtration [14-16]. Its purity, charge density and molecular integrity have been confirmed by reverse polarity capillary electrophoresis [16]. 20-kDaPS consists mainly of glucose and N-acetylglucosamine, and is partially sulfated. Proposed structure of 20$\mathrm{kDaPS}$ is 30-35 molecules of glucose, 1-3 molecules of xylose and fucose, 61-65 molecules of glucosamine (6$7 \mathrm{~N}$-sulfated) (also perhaps $\mathrm{N}$ - acetyl- and/or succinated) and 3-4 molecules of glucuronic acid [14]. This polysaccharide represents $60-65 \%$ of total slime carbohydrate and seems to be one of the main antigenic components of slime $[17,18]$. Immunization of rabbits with purified 20$\mathrm{kDaPS}$ elicits production of antibodies reacting specifically with 20-kDaPS and biofilm-producing reference strain ATCC35983 (RP12) and other biofilm-producing clinical $S$. epidermidis strains, but not with other CoNS or S. aureus clinical isolates [19]. Protective value of 20-kDaPS antibodies has been proven in experimental keratitis protocols, where passive and active immunization of rabbits with 20-kDaPS antigen and anti-20-kDaPS exhibit beneficial properties [20-22]. Administration of intravenous immunoglobulin preparations with high anti-20-kDaPS titers in preterm neonates reduces risk of bacteraemia caused by biofilm-producing S. epidermidis [23]. Finally, experimental data suggest that $20-\mathrm{kDaPS}$ is associated with attachment of S. epidermidis to endothelial cells [24].

Several other polysaccharide molecules have been associated with biofilm accumulation or initial adherence on surfaces, such as PS/A (Capsular Polysaccharide Adhesin) or PNSG (Poly N-Succinyl Glucosamine), finally defined as PNAG [25-28], and SAA (Slime Associated Antigen)
[29,30]. As other polysaccharide molecules associated with S. epidermidis' pathogenesis turned out to be identical or related to PIA [31-36], the aim of this study was to define the relation of $20-\mathrm{kDaPS}$ and PIA using isogenic mutants with Tn917-insertions in various locations in icaADBC, specific antisera and specific glycosidase and chemical treatments. In addition, in vitro experiments were conducted exploring 20-kDaPS biological interference in phagocytosis by human macrophages.

\section{Results}

\section{Detection of 20-kDaPS, PIA expression and}

\section{icaADBC-genotype in clinical CoNS isolates}

Among fifty (50) clinical S. epidermidis strains, eighteen (36\%) were found $\mathrm{ica}^{+}$biofilm ${ }^{+} 20-\mathrm{kDaPS}^{+}$, ten $(20 \%)$ ica ${ }^{-}$biofilm ${ }^{-}$20-kDaPS, six (12\%) ica $^{+}$biofilm ${ }^{-}$20$\mathrm{kDaPS}^{+}$, six (12\%) ica biofilm ${ }^{-} 20-\mathrm{kDaPS}^{+}$, five $(10 \%) \mathrm{ica}$ ${ }^{+}$biofilm $^{-} 20-\mathrm{kDaPS}^{-}$and five (10\%) strains ica ${ }^{+}$biofilm $^{+}$ 20-kDaPS- All other CoNS $(\mathrm{n}=25)$ were $\mathrm{ica}^{-}$biofilm 20-kDaPS ${ }^{-}$. All $\mathrm{ica}^{+}$biofilm $^{+}$S. epidermidis strains were PIA-positive by specific immunofluorescence test, whereas, $i c a^{-}$biofilm ${ }^{-}$or $i c a^{+}$biofilm $^{-}$strains were PIAnegative. In our $S$. epidermidis strain collection, $46 \%$ $(\mathrm{n}=23)$ were PIA positive and $60 \%(\mathrm{n}=30)$ were 20 $\mathrm{kDaPS}$ positive. IcaADBC prevalence in our collection was $68 \%$, whereas $46 \%$ of $S$. epidermidis strains were biofilm-producing. 20-kDaPS expression among $\mathrm{ica}^{+} S$. epidermidis strains was $70 \% \quad\left(\begin{array}{lll}24 & \text { ica }^{+} & 20-\mathrm{kDaPS}^{+}\end{array}\right.$ amongst $34 \mathrm{ica}^{+}$S. epidermidis strains), whereas, 20$\mathrm{kDaPS}$ expression among ica strains was 37\% (6 ica$20-\mathrm{kDaPS}^{+}$amongst 16 ica $^{-}$S. epidermidis strains). 20$\mathrm{kDaPS}$ expression in relation to biofilm formation reveals that $78 \%$ of biofilm-producing S. epidermidis strains expressed 20-kDaPS (18 biofilm ${ }^{+} 20-\mathrm{kDaPS}^{+}$in 23 biofilm $^{+}$S. epidermidis strains), whereas, $44 \%$ of biofilm-negative strains were $20-\mathrm{kDaPS}$ positive (12 biofilm ${ }^{-}$ $20-\mathrm{kDaPS}^{+}$of 27 biofilm $^{-}$S. epidermidis strains). These results show that the majority of clinical $S$. epidermidis isolates express $20-\mathrm{kDaPS}$ and that there is no strict correlation of $i c a A D B C$-genotype or biofilm phenotype and expression of 20-kDaPS.

\section{Expression of 20-kDaPS and PIA by S. epidermidis strains with known genetic backgrounds}

Using an indirect immunofluorescence test with specific anti-PIA antiserum S. epidermidis strains 1457, 8400, and 9142 were shown to express PIA, while the isogenic icaA-insertion mutants 1457-M10, M24 and 8400-M10 and isogenic icaC-insertion mutants M22 and M23 did not express PIA. Similarly, S. epidermidis 5179, 5179R1 and 1585 did not synthesize PIA as in the former two strains icaADBC is inactivated through insertion of IS257 [37], while 1585 is icaADBC-negative. Using specific anti-20-kDaPS antiserum S. epidermidis 1457, 
1457-M10, M22, M23, M24, 8400, 8400-M10, 9142, 5179, 5179R1 were 20-kDaPS positive, whereas, S. epidermidis strain 1585 was $20-\mathrm{kDaPS}$ negative. A representative immunofluorescence test with anti-PIA and anti-20-kDaPS antisera, comparing S. epidermidis 1457 and 1457-M10, is displayed in Figure 1. An identical expression pattern of 20-kDaPS was independently demonstrated for these strains using specific ELISA, excluding that there are significant quantitative differences in 20$\mathrm{kDaPS}$ antigen expression between the isogenic mutant strain pairs (Figure 2). 20-kDaPS detection in transposon mutants of S. epidermidis 1457-M10, M22, M23, M24 is shown in Figure 3. Inactivation of icaA in mutant 1457 M10 and of icaC in mutants M22 and M23 lead to biofilm negative and PIA negative phenotype, but did not alter $20-\mathrm{kDaPS}$ antigen detection. The fact that mutant M24, where the transposon is oriented in the opposite transcriptional direction than the $i c a A D B C$ operon and no ica specific transcript can be identified, still expressed $20-\mathrm{kDaPS}$ provide clear proof that $20-\mathrm{kDaPS}$ synthesis is independent of the icaADBC operon.

\section{Influence of chemical and enzymatic treatments on antigen detection by immunofluorescence and on biofilm integrity}

Periodate oxidation led to abolishment of antigenic reactivity of PIA, whereas 20-kDaPS preserved its antigenic properties (Figures $4 \mathrm{e}$ and $4 \mathrm{f}$ ). Treatment with dispersin B (DspB) completely destroyed antigenic reactivity of PIA within one hour of incubation. DspB is a hexosaminidase ( $\beta$ - $\mathrm{N}$-acetylglucosaminidase) produced by the oral pathogen Aggregatibacter actinomycetemcomitans, which specifically cleaves $\beta$-1,6-linked $\mathrm{N}$-acetylglucosamine polymer disrupting PIA chain $[38,39]$. In contrast, DspB does not alter 20-kDaPS antigenic properties (Figures $4 \mathrm{~g}$ and 4h). Parallel to PIA destruction, biofilm structure is disrupted after periodate oxidation and DspB treatments and large clumps are substituted by small clumps or single and double cells, still detectable by anti-20-kDaPS antiserum (Figure 4). Finally, the fact that PIA and $20-\mathrm{kDaPS}$ retain their antigenic properties after proteinase $\mathrm{K}$ digestion is consistent with their polysaccharide nature (Figures $4 \mathrm{c}$ and $4 \mathrm{~d}$ ). Integrity of biofilm, formed on 96-well cell culture plates, to treatment with proteinase $\mathrm{K}$, sodium meta-periodate and $\mathrm{DspB}$ was also studied. All biofilms were susceptible to sodium meta-periodate and DspB, whereas, addition of proteinase $\mathrm{K}$ did not affect biofilm stability. Thus, biofilm production in our strain collection is mediated mainly through PIA, as was shown in other studies [40-42]. In addition, 20-kDaPS presence does not relate to biofilm formation as agents, such as sodium meta-periodate and DspB that destroy biofilm integrity, do not affect antigenic properties of $20-\mathrm{kDaPS}$.
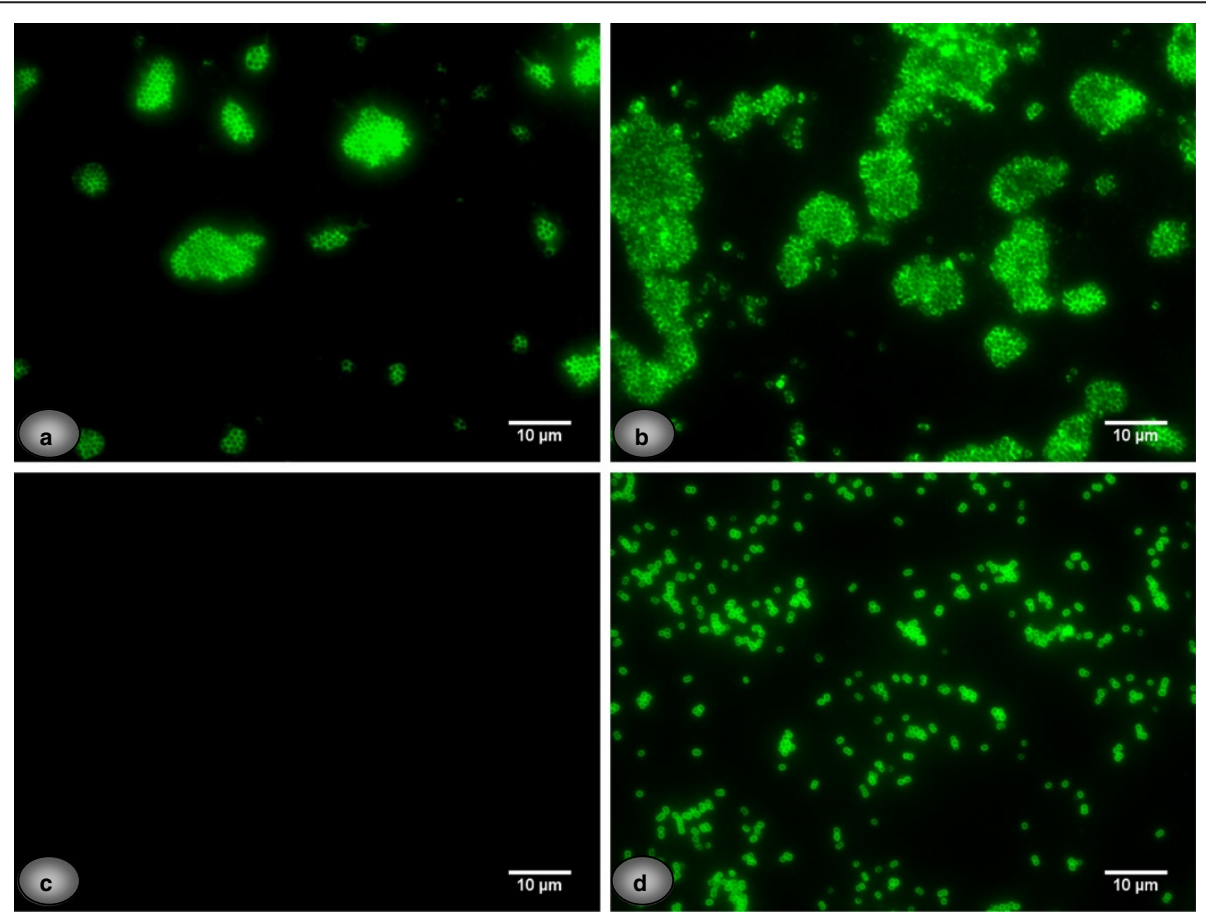

Figure 1 Immunofluorescence detection of PIA and 20-kDaPS on reference strains. Immunofluorescence detection of PIA (a, c) and 20-kDaPS (b, d) on S. epidermidis 1457 (a, b) and icaA-insertion mutant S. epidermidis 1457-M10 (c, d), grown in TSB medium, utilizing PIA and 20-kDaPS specific rabbit antisera, respectively. 


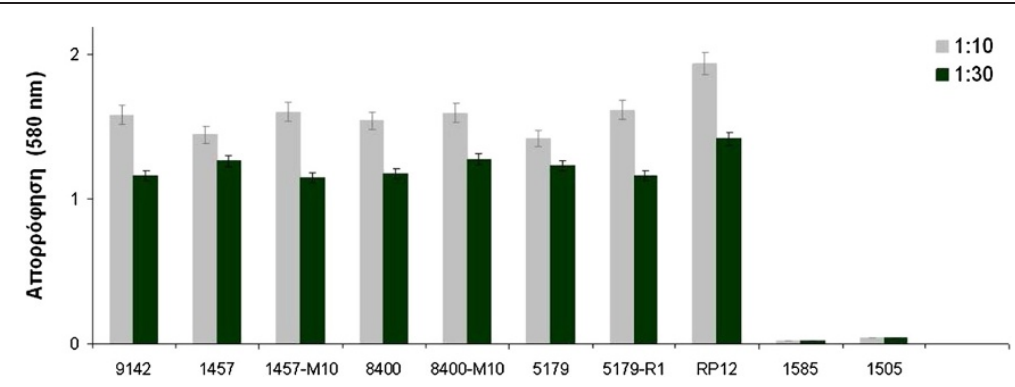

Figure 2 20-kDaPS expression in reference strains. Microtiter plates were coated with bacterial suspensions (absorbance ${ }_{578}=1.0$ ) diluted 1:10 and 1:30, respectively, in PBS and incubated with 20-kDaPS antiserum at a 1:3,000 dilution. Results represent mean absorbance values \pm SDs for two independent experiments performed in triplicate.
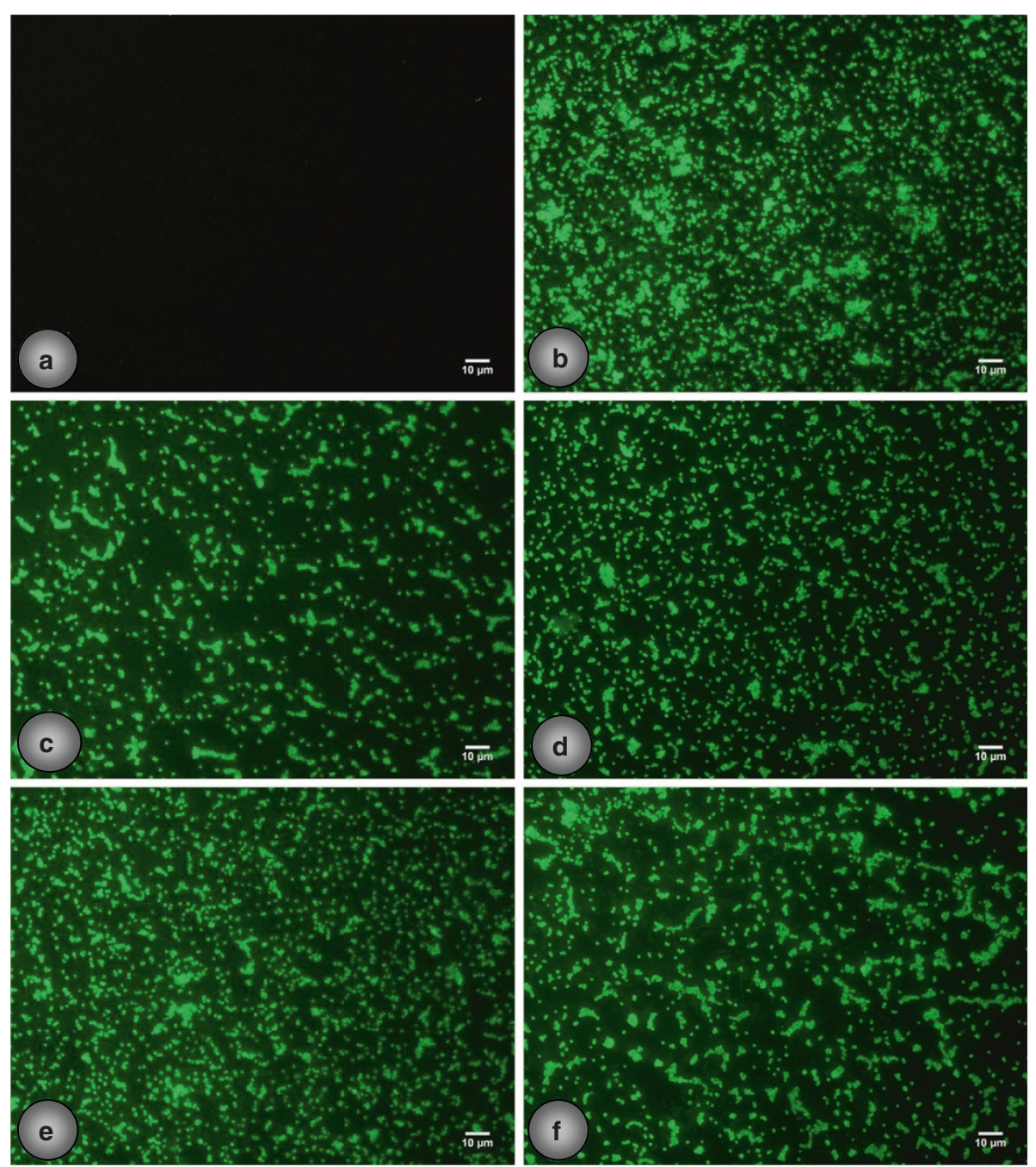

Figure 3 Immunofluorescence detection of 20-kDaPS on selected strains. Immunofluorescence detection of 20-kDaPS on S. epidermidis (a) 1505, (b) 1457, (c) 1457-M10, (d) M22, (e) M23 and (f) M24. Scale bar stands for $10 \mu \mathrm{m}$. 

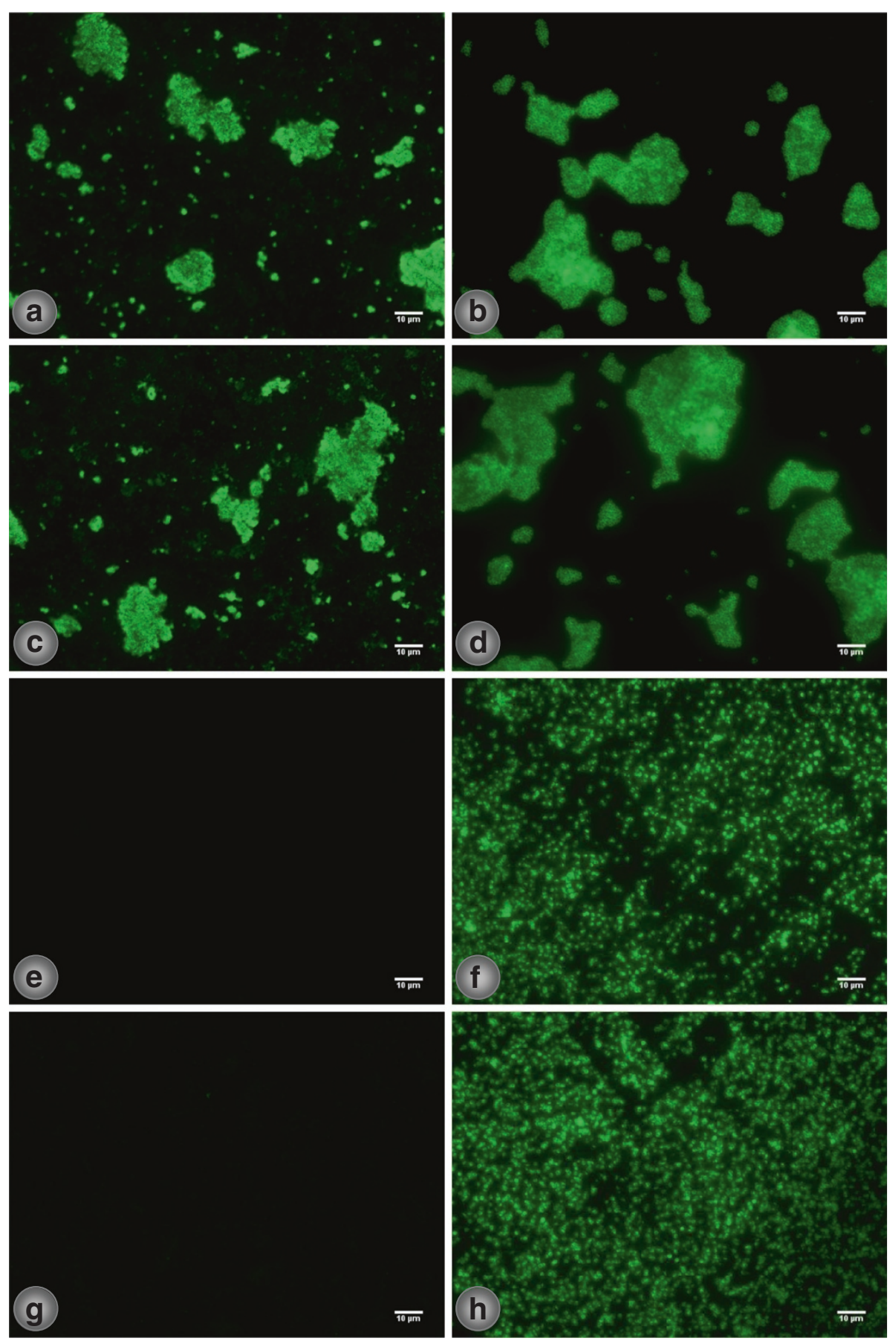

Figure 4 Influence of proteinase $\mathrm{K}$, periodate and DspB treatments on PIA and 20-kDaPS. Immunofluorescence detection of PIA $(\mathbf{a}, \mathbf{c}, \mathbf{e}, \mathbf{g})$ and 20-kDaPS (b, d, $\mathbf{f}, \mathbf{h})$ on S. epidermidis 1457 grown as biofilm $(\mathbf{a}, \mathbf{b})$ after treatment with proteinase K (c, d), sodium meta-periodate $(\mathbf{e}, \mathbf{f})$ and $\operatorname{DspB}(\mathbf{g}, \mathbf{h})$

\section{Lack of co-purification of 20-kDaPS with PIA} polysaccharide I in Q-Sepharose anion-exchange chromatography

Clarified crude bacterial extracts obtained after bacterial sonication were tested for presence of PIA and 20-kDaPS reactivity by ELISA using anti-PIA and anti-20-kDaPS rabbit antisera, respectively (Figure 5 ). Under the conditions employed, in the crude extract consistently higher absorbance values were obtained with the 20-kDaPS specific antiserum as compared to the anti-PIA specific antiserum. The crude extract was applied to a Q-Sepharose column as described in Materials and Methods. Under 


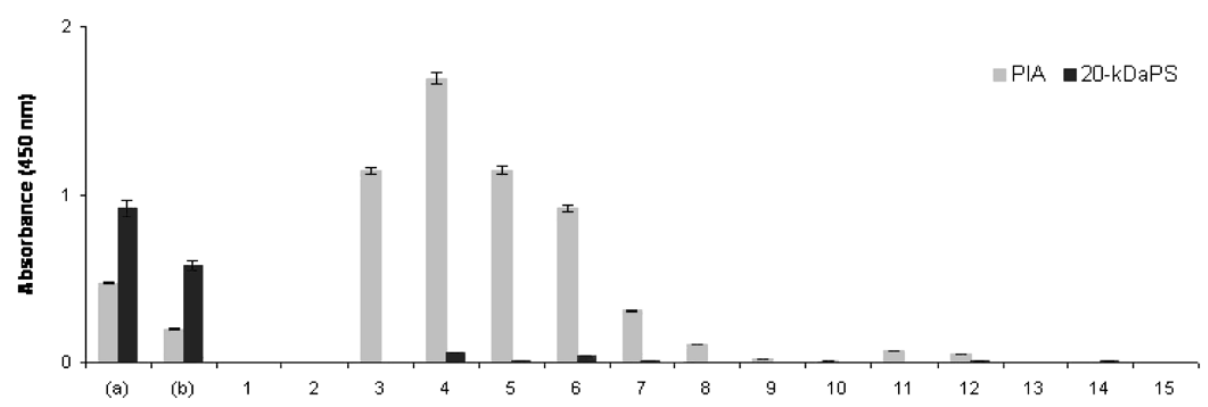

Figure 5 PIA and 20-kDaPS detection in clarified bacterial extracts and Q-Sepharose eluted fractions. PIA and 20-kDaPS detection in clarified bacterial extracts diluted 1:500 (a) and 1:2,000 (b) and Q-Sepharose column fractions (1-15) diluted 1:20. PIA and 20-kDaPS rabbit antisera were used at 1:800 and 1:3,000 dilutions, respectively. Presented data represent mean absorbance values \pm SDs for two independent experiments performed in triplicate.

these conditions the majority of PIA (approx. 80\%) did not bind to the columns, but was immediately eluted. This PIA antigen fraction is referred to as polysaccharide I of PIA [4]. However, in the fractions representing the PIA antigenic peak reactivity with the specific anti-20-kDaPS antiserum was negligible indicating that $20-\mathrm{kDaPS}$ does not co-purify with polysaccharide I of PIA. Additionally, this excludes significant cross reactivity of the 20-kDaPS antiserum with epitopes present on PIA.

\section{PIA and 20-kDaPS antisera do not cross-react with each-other}

In order to identify any cross reactivity among 20-kDaPS antiserum and PIA antigen and vice versa, absorption studies were performed. PIA-specific antiserum was absorbed by S. epidermidis 1457 ( $\mathrm{PIA}^{+} 20-\mathrm{kDaPS}^{+}$) strain, as described in Methods. Absorbed antiserum was incubated with 1457 on immunofluorescence slides and achievement of complete absorption was confirmed. Furthermore, absorbed antiserum did not detect PIA on RP12 (PIA $\left.{ }^{+} 20-\mathrm{kDaPS}^{+}\right), 1477\left(\mathrm{PIA}^{+} 20-\mathrm{kDaPS}^{+}\right)$and 1510 (PIA $^{+} 20-\mathrm{kDaPS}^{-}$) S. epidermidis strains. PIA-specific antiserum was also absorbed by S. epidermidis 1510 $\left(\mathrm{PIA}^{+} 20-\mathrm{kDaPS}^{-}\right)$and immunofluorescence tests performed with S. epidermidis RP12, 1457 and 1477. No remaining anti-PIA reactivity was observed with any strain using the absorbed antiserum. Finally, PIA-specific antiserum absorbed with S. epidermidis 1522 (PIA ${ }^{-} 20-$ $\mathrm{kDaPS}^{+}$) retains all reactivity to S. epidermidis 1457 , RP12 and 1477 strains. In case that PIA antiserum reacted - even weakly - with 20-kDaPS antigen, incubation of PIA antiserum with strain 1522 bearing 20$\mathrm{kDaPS}$ antigen, would lead to absorption of anti-PIA antibodies and no anti-PIA reactivity would remain. A selection of analogous experiments was performed regarding anti-20kDaPS serum, as shown in Table 1.

Table 1 Cross absorption experiment

\begin{tabular}{|c|c|c|c|c|c|c|c|c|}
\hline & \multicolumn{4}{|c|}{ anti-PIA serum absorbed by } & \multicolumn{4}{|c|}{ anti-20 kDa PS serum absorbed by } \\
\hline & $1457^{a}$ & $1510^{a}$ & $15222^{a}$ & & $1457-\mathrm{M} 0^{\mathrm{a}}$ & $1522^{a}$ & $1510^{a}$ & $1505^{\mathrm{a}}$ \\
\hline & $\mathrm{PIA}^{+} 20 \mathrm{kDaPS}^{+}$ & $\mathrm{PIA}^{+} 20 \mathrm{kDaPS}$ & $\mathrm{PIA}^{-} 20 \mathrm{kDaPS}^{+}$ & & $\mathrm{PIA}^{-} 20 \mathrm{kDaPS}^{+}$ & $\mathrm{PIA}^{-20 k D a P S}{ }^{+}$ & $\mathrm{PIA}^{+} 20 \mathrm{kDaPS}$ & $\mathrm{PIA}^{-} 20 \mathrm{kDaPS}$ \\
\hline $1457^{b}$ & $-{ }^{c}$ & - & $+{ }^{d}$ & $1457-M 10^{b}$ & - & - & + & + \\
\hline $\mathrm{PIA}^{+} 20 \mathrm{kDaPS}^{+}$ & & & & $\mathrm{PIA}^{-} 20 \mathrm{kDaPS}^{+}$ & & & & \\
\hline $1510^{b}$ & - & - & + & $1457^{b}$ & - & - & + & + \\
\hline $\mathrm{PIA}^{+} 20 \mathrm{kDaPS}^{-}$ & & & & $\mathrm{PIA}^{+} 20 \mathrm{kDaPS}{ }^{+}$ & & & & \\
\hline RP12 & - & - & + & $\mathbf{R P} 12^{b}$ & - & - & + & + \\
\hline $\mathrm{PIA}^{+} 20 \mathrm{kDaPS}^{+}$ & & & & $\mathrm{PIA}^{+} 20 \mathrm{kDaPS}{ }^{+}$ & & & & \\
\hline $1477^{b}$ & - & - & + & $1522^{b}$ & - & - & + & + \\
\hline \multirow[t]{3}{*}{$\mathrm{PIA}^{+} 20 \mathrm{kDaPS}^{+}$} & & & & $\mathrm{PIA}^{-20 k D a P S}{ }^{+}$ & & & & \\
\hline & & & & $1477^{b}$ & - & - & + & + \\
\hline & & & & $\mathrm{PIA}^{+} 20 \mathrm{kDaPS}^{+}$ & & & & \\
\hline
\end{tabular}

${ }^{a}$ Strains used for absorption of specific antisera, ${ }^{b}$ Strains applied on immunofluorescence slide, ${ }^{c}$ no fluorescence indicated no residual reactivity for specific antigen, ${ }^{d}$ fluorescence indicated reactivity for specific antigen. 
Table 2 Immunofluorescence upon prolonged culture in different chemically defined media

\begin{tabular}{|c|c|c|c|c|c|}
\hline & biofilm & anti-PIA & anti- & 20-kDaPS & \\
\hline & 1457 & 1457 & 1457 & $1457-\mathrm{M} 10$ & $\mathrm{RP12}$ \\
\hline RPMI1640 & weak & $+^{*}$ & ++ & ++ & ++ \\
\hline RPMI1640 + Glutamine & weak & $+^{*}$ & ++ & ++ & ++ \\
\hline IMDM & weak & $+^{*}$ & ++ & ++ & ++ \\
\hline TSB & strong & ++ & ++ & ++ & ++ \\
\hline TSB w/o Dextrose & negative & - & $t^{\circ}$ & $t^{\circ}$ & $+^{\circ}$ \\
\hline Blood agar & & $+^{*}$ & ++ & ++ & ++ \\
\hline
\end{tabular}

Synthesis of 20-kDaPS and PIA in different culture media In order to explore possible polysaccharide synthesis dependence on certain constituents of culture media, 20$\mathrm{kDaPS}$ and PIA presence upon prolonged culture in different culture media was studied. 20-kDaPS expression was not abolished after long time incubation of bacteria in any of the selected media (RPMI1640, RPMI1640 + glutamine, IMDM, TSB, TSB w/o dextrose and on blood agar plates). 20-kDaPS antiserum revealed strong reactivity to bacterial cells growing in all media with the exception of TSB w/o dextrose where only a percentage of bacterial cells express 20-kDaPS. Regarding PIA synthesis, TSB seems superior to RPMI 1640, RPMI 1640 + glutamine and IMDM upon prolonged consecutive subcultures, whereas PIA expression was almost abolished in TSB lacking dextrose, in accordance to previous reports [7]. In addition, PIA presence was strongly associated to biofilm formation. Biofilms formed in RPMI1640, RPMI1640 + glutamine and IMDM were more susceptible to mechanic disruption following agitation by vortex and disintegration into small clumps (Table 2).

\section{Impact of 20-kDaPS on bacterial endocytosis}

Differences in phagocytosis between $S$. epidermidis reference strain ATCC35983 and the clinical 20-kDaPS negative strain 1505 were observed $(48,300 \pm 2,400$ cfu $v s$ $68,800 \pm 4,700 \mathrm{cfu}$, respectively, $p<0.05)$. Phagocytosis experiments were performed without addition of exogenous complement. Preincubation of non-20kDaPS-producing strain with different concentrations of 20-kDaPS inhibits endocytosis (Figure 6). Specifically, preincubation of non-20kDaPS-producing strain with 20-kDaPS $(0,15$, $30,60,180 \mu \mathrm{g} / \mathrm{mL}$ ) reduces the number of endocytosed bacteria from $76,500 \pm 7,400$ to $54,000 \pm 1,300$, $40,000 \pm 2,271,9,100 \pm 2,193,4,100 \pm 793$ bacteria/well, respectively. Differences are statistically significant in all above $20-\mathrm{kDaPS}$ concentrations.Inhibition of endocytosis takes place at a dose dependent manner between 0 and $60 \mu \mathrm{g} / \mathrm{mL}$ (Figure 7). On the contrary, 20-kDaPS antiserum increases endocytosis of 20-kDaPS-producing ATCC35983 strain $\mathrm{ca} 10$ fold, as compared to bacteria preincubated with preimmune serum $(516,800 \pm 52,500$ cfu vs 52,800 $\pm 28,800$, $p<0.005)$. Preincubation with preimmune antiserum did not alter endocytosis, as compared to bacteria preincubated with PBS $(48,300 \pm 2,400$ cfu vs $52,800 \pm 28,800 \mathrm{cfu})$. In terms of $S$. epidermidis clinical isolate 1505 , preincubation with preimmune antiserum seems to enhance endocytosis, as compared to bacteria preincubated with PBS $(101,600 \pm 10,400$ vs $68,800 \pm 8,700$ cfu, respectively, $p$ $<0.05$ ), but preincubation with $20-\mathrm{kDaPS}$ antiserum does not further increase endocytosis, as compared to bacteria preincubated with preimmune serum $(98,300 \pm 17,900 \mathrm{cfu}$ vs $101,600 \pm 10,400 \mathrm{cfu}, p>0.05)$. This phenomenon may be associated with the presence of other anti-staphylococcal antibodies in rabbit serum. Prior to immunization, rabbit serum was collected and tested by ELISA for reactivity to $20-\mathrm{kDaPS}$ in order to exclude pre-existence of $20-\mathrm{kDaPS}$

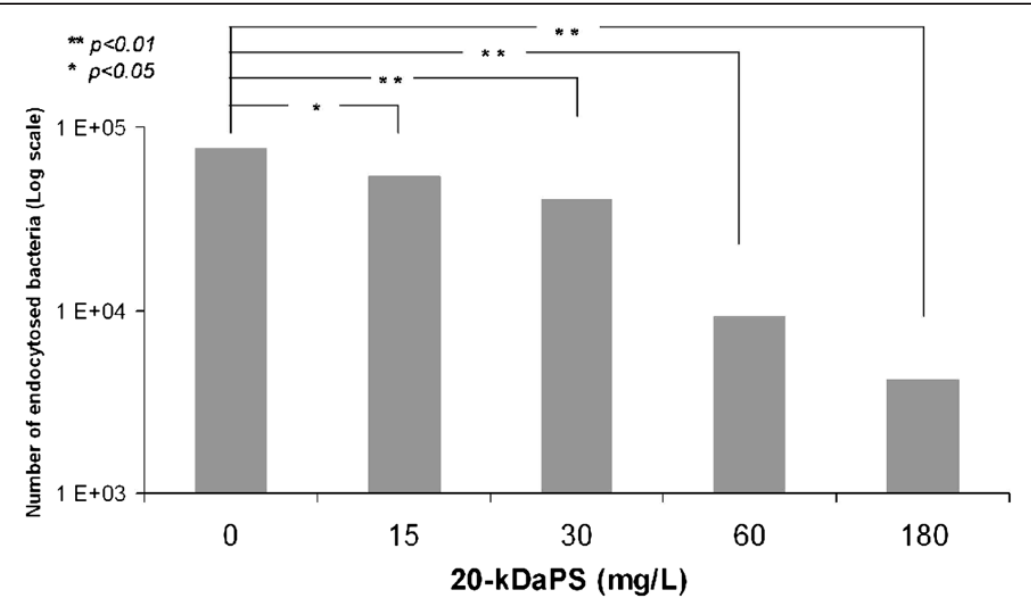

Figure 6 Impact of 20-kDaPS on endocytosis of S. epidermidis by human macrophages. Bacterial suspensions of non-20-kDaPS producing S. epidermidis clinical strain, preincubated with different concentrations of 20-kDaPS, were added to human macrophages. The number of endocytosed bacteria was counted by serial dilutions of cell lysates on blood agar. All experiments were repeated five times. 


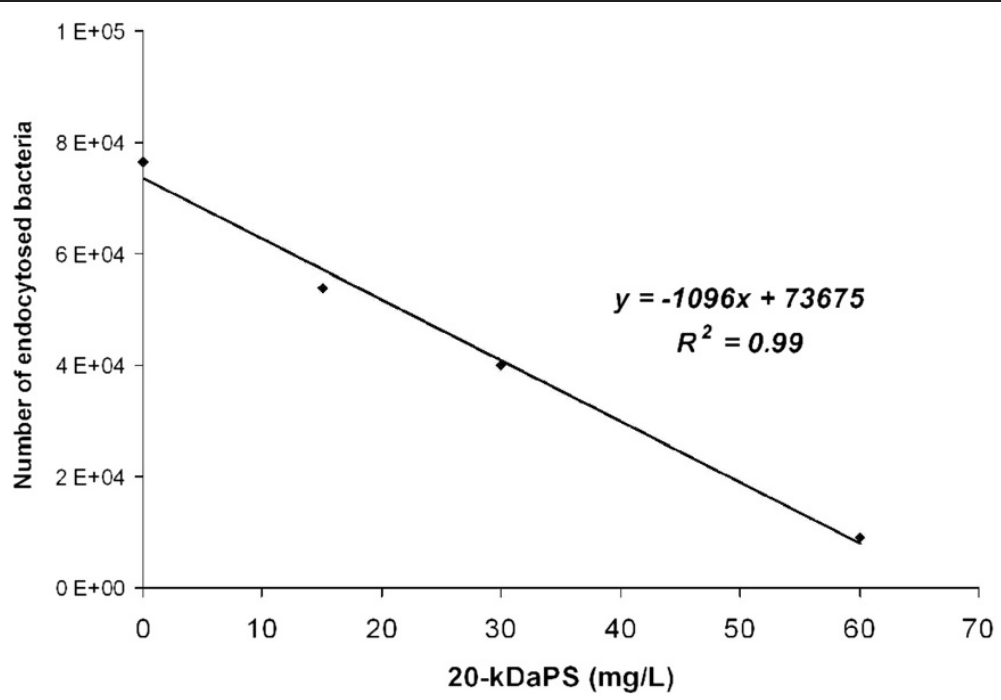

Figure 7 20-kDaPS inhibits endocytosis of S. epidermidis in a dose-dependent manner. Standard curve obtained by counting the number of endocytosed bacteria preincubating with increasing amounts of 20-kDaPS $(0,15,30,60 \mathrm{mg} / \mathrm{L})\left(\mathrm{y}=-1096 \mathrm{x}+73675, R^{2}=0.99\right.$.

specific antibodies. Low titers of antibodies to various staphylococcal strains, S. epidermidis and S. aureus, are present in preimmune serum (data not shown) and may be responsible for the observed effect. A representative experiment of five similar ones is presented in Figure 8.

\section{Discussion}

Staphylococcus epidermidis is an important pathogen [43] and extracellular polysaccharides as well as a number of surface proteins contributing to bacterial attachment and biofilm formation have been extensively studied. Analysis of S. epidermidis' polysaccharides has been associated with difficulties, however, it is now clear that, despite some possible variation, PIA, and other analogue polysaccharides such as PS/A, PNSG, PNAG, and SAA are chemically closely related if not identical and represent the same chemical entity, namely PIA. This is the first time shown that $20-\mathrm{kDaPS}$ is discrete from PIA and this statement is based on concrete basis.

Transposon insertion in icaADBC, the locus encoding synthetic enzymes for PIA synthesis, does not abrogate production of 20-kDaPS. In mutant 1457-M10 in which Tn917 was inserted in icaA in the same transcriptional orientation, outward directed transcription resulted in transcripts comprising the complete sequences of icaD, $i c a B$ and icaC [44]. Expression of 20-kDaPS in mutant $1457-M 10$ where icaA synthesis is inhibited and in mutant M22 and M3 where icaC expression was inhibited shows that $20-\mathrm{kDaPS}$ synthesis does not require an intact icaA or icaC gene. The fact that $20-\mathrm{kDaPS}$ was detected in M24, where Tn917 was inserted in the opposite transcriptional direction to the ica operon and no-ica specific transcripts were identified [44], provides evidence that 20-kDaPS synthesis is independent of ica operon. In contrast, PIA synthesis is completely inhibited not only by the disruption of the entire icaADBC operon but also by the isolated inhibition of icaA (M10) and icaC (M22, M23) gene expression.

Proteinase $\mathrm{K}$ does not disrupt antigenic properties of $20-\mathrm{kDaPS}$ reconfirming its polysaccharide nature. Furthermore, DspB, which specifically cleaves $\beta$-1,6-linked $\mathrm{N}$-acetylglucosamine polymer disrupting PIA chain [38,39], did not affect 20-kDaPS. Although sodium meta-periodate is an agent commonly used to disrupt polysaccharide molecules, it did not affect integrity of $20-\mathrm{kDaPS}$ antigen. Taking into account that periodate preferably degrades cis-diols, it is suggested that monomeric units of the polysaccharide core form glycosidic bonds between the anomeric $\mathrm{C}-1$ and the $\mathrm{C}-3$ or $\mathrm{C}-4$. This is not the case for PIA, where a $\beta-1,6$-glycosidic bond is present leaving free vicinal hydroxyl groups of glucosamine at $\mathrm{C}-3$ and $\mathrm{C}-4$. The above structural data suggest that $20-\mathrm{kDa}$ PS and PIA are two discrete and different polysaccharides. Preliminary data in our laboratories showed that $20-\mathrm{kDaPS}$ is not affected upon treatment with glycosaminoglycan- degrading enzymes (heparin lyases, keratanases and chondroitinases), suggesting a non glycosaminoglycan-related structure.

Absence of 20-kDaPS in Q-Sepharose fractions containing maximum PIA reactivity is due to different physicochemical properties among the two molecules. QSepharose is a strong anion-exchanger which retains negatively charged molecules. Whereas PIA is eluting, 20-kDaPS may be strongly retained by the column due to its negative charges. Aforementioned differentiation was expected as different isolation procedures are used for the two polysaccharides. As previously described $[16,19], \quad 20-\mathrm{kDaPS}$ is obtained from bacterial 


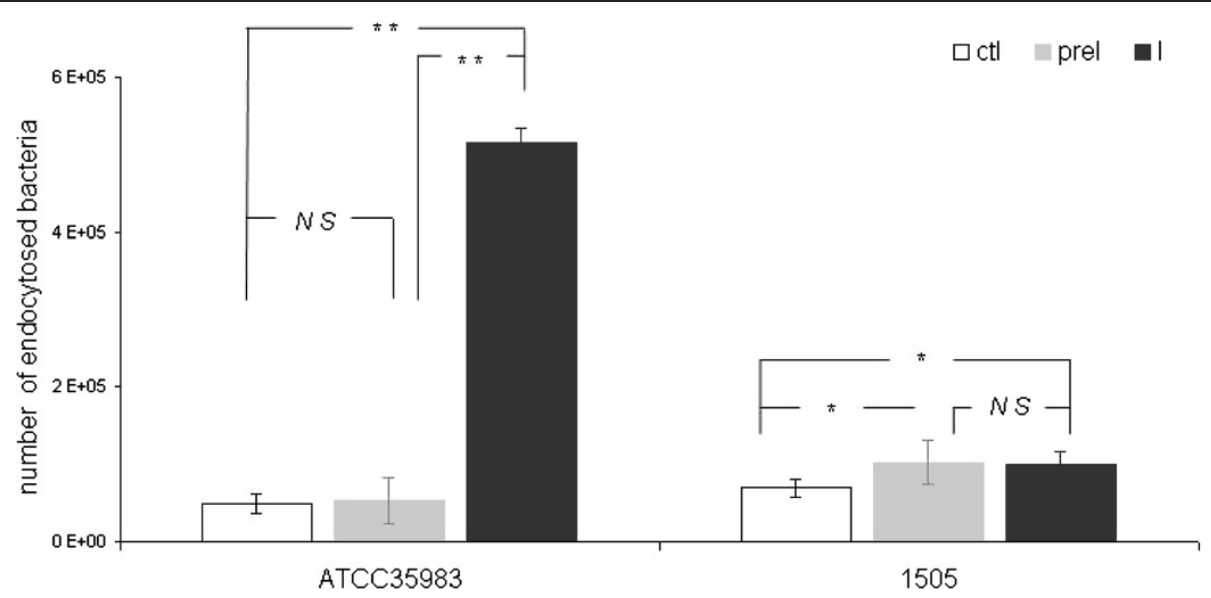

Figure 8 Impact of 20-kDaPS antiserum on endocytosis of S. epidermidis by human macrophages. Bacterial suspensions of 20-kDaPSproducing S. epidermidis reference strain ATCC35983 and non-20-kDaPS producing S. epidermidis clinical strain 1505 preincubated with PBS (ctl), preimmune serum (prel), and 20-kDaPS antiserum (I) were added to human macrophages. The number of endocytosed bacteria was counted by serial dilutions of cell lysates on blood agar. Columns represent mean values of endocytosed bacteria from a representative experiment out of five similar ones performed in triplicate. $\left(^{*}\right) p<0.05,\left(^{* *}\right) p<0.005$, (NS) $p>0.05$.

extracellular matrix using a linear $\mathrm{NaCl}$ gradient on DEAE-Sephacel and elutes at $0.5-0.7 \mathrm{M} \mathrm{NaCl}$.

Presented data suggest that $20-\mathrm{kDaPS}$ inhibits endocytosis of S. epidermidis bacterial cells at a dosedependent manner. Similarly, PIA provides protection against opsonophagocytosis and activity of anti-microbial peptides $[9,10]$. In the absence of specific opsonizing antibodies, macrophages are able to clear pathogens by innate immune receptors, such as the group of molecular pattern recognition receptors (PRR), collectively known as scavenger receptors [45]. 20-kDaPS may interfere with or mask staphylococcal antigen(s) promoting phagocytosis [46]; on the other hand, it may interact with a receptor that does not facilitate phagocytosis. Adhesion receptors and phagocytosis receptors can both activate and inhibit each other functions [47]. It has been previously shown that $20-\mathrm{kDaPS}$ promotes adhesion to human endothelial cells and this interaction is blocked upon addition of anti-20kDaPS antibodies. Comparable data were acquired by using human macrophages (data not shown), indicating the presence of a specific ligand for 20-kDaPS on human cells. Adherence of unopsonized bacteria to macrophages does not preclude internalization [48-51]. Nonopsonic binding of pathogens to host phagocytic cells may not always result in phagocytosis, however, it may serve an important role in the immune response [52]

Nevertheless, phagocytic activity of macrophages is greatly enhanced if specific antibodies are attached to the pathogen [53]. 20-kDaPS antiserum do not exhibit any cross reactivity with PIA. Antibodies against PNSG and PIA have been found completely cross-reactive [31]. As $20-\mathrm{kDaPS}$ antiserum reacts specifically and strictly with 20-kDaPS, observed biologic properties concern exclusively this entity. Our data show that 20-kDaPS antiserum exhibits opsonic properties as it increases endocytosis of S. epidermidis ATCC35983 by human macrophages. Several surface molecules have been studied as potential antibody targets in order to enhance phagocytic potential of monocytes/macrophages. Opsonic activity of antibodies to S. epidermidis Fbe and AtlE has been demonstrated in a study where fresh alveolar macrophages from rat ingested and killed S. epidermidis opsonized with anti-Fbe antibodies (raised in rabbit, rat or sheep) to a much higher extent than they ingested and killed nonopsonized bacteria or bacteria opsonized with antibodies directed against AtlE or Embp [53]. Also, a chimerized (murine/human) monoclonal antibody against lipoteichoic acid that was proven protective for CoNS and $S$. aureus bacteremia in animal models has been also tested to humans [54]. In contrast, antibodies to accumulation-associated protein and lipoteichoic acid had no opsonic activity in vitro and did not protect mice against experimental biomaterial-associated infections [55]. Although, conjugate vaccines based on PIA/PNAG have been shown to be beneficial in animal models [56-60], several doubts for their use in human trials have been documented [61,62]. Thus, more and extensive investigations are needed to evaluate the potential use of $20-\mathrm{kDaPS}$ in conjugate vaccines.

\section{Conclusions}

This is the first study providing concrete data that 20$\mathrm{kDaPS}$ is a unique polysaccharide molecule discrete from PIA. 20-kDaPS exhibits antiphagocytic properties that may be shown to play a role in pathogenicity. Further work is in progress to establish a role in conjugate vaccine development. 
Table 3 S. epidermidis reference and clinical strains used in the present study

\begin{tabular}{|c|c|c|c|c|}
\hline \multicolumn{5}{|l|}{ S. epidermidis strains } \\
\hline 1457 & biofilm ${ }^{+} P I A^{+}$ & $i a^{+}$ & $20-\mathrm{kDaPS}^{+}$ & Mack et al., 1992 \\
\hline 1457-M10 & biofilm PIA & icaA::Tn917 & $20-\mathrm{kDaPS}^{+}$ & Mack et al., 1994 \\
\hline$M 22$ & biofilmPIA- & icaC::Tn917 & $20-\mathrm{kDaPS}^{+}$ & Mack et al., 2000 \\
\hline M23 & biofilm ${ }^{-} I A^{-}$ & icaC::Tn917 & $20-\mathrm{kDaPS}^{+}$ & Mack et al., 2000 \\
\hline M24 & biofilmPIA- & icaA::Tn917 & $20-\mathrm{kDaPS}^{+}$ & Mack et al., 2000 \\
\hline 8400 & biofilm ${ }^{+} \mathrm{PIA}^{+}$ & $i \mathrm{Ca}^{+}$ & $20-\mathrm{kDaPS}^{+}$ & Mack et al., 1992 \\
\hline 8400-M10 & biofilmPIA- & icaA::Tn917 & $20-\mathrm{kDaPS}^{+}$ & Mack et al., 1999 \\
\hline 9142 & biofilm ${ }^{+}$PIA ${ }^{+}$ & $i c a^{+}$ & 20-kDaPS ${ }^{+}$ & Mack et al., 1992 \\
\hline 5179 & biofilmPIA- & icaA::/S257 & $20-\mathrm{kDaPS}^{+}$ & Mack et al., 1992 \\
\hline $5179 \mathrm{R} 1$ & biofilm ${ }^{+} P I A^{-}$ & icaA::IS257 aap ${ }^{+}$ & $20-\mathrm{kDaPS}^{+}$ & Rohde et al., 2005 \\
\hline 1585 & biofilm-PIA & ica- & 20-kDaPS- & Rohde et al., 2005 \\
\hline ATCC35983 (RP12) & biofilm ${ }^{+} \mathrm{PIA}^{+}$ & $i \mathrm{ca}^{+}$ & $20-\mathrm{kDaPS}^{+}$ & Reference strain \\
\hline ATCC35984(RP62A) & biofilm ${ }^{+} P I A^{+}$ & $i \mathrm{ca}^{+}$ & $20-\mathrm{kDaPS}^{+}$ & Reference strain \\
\hline 1477 & biofilm ${ }^{+} \mathrm{PIA}^{+}$ & $i \mathrm{Ca}^{+}$ & $20-\mathrm{kDaPS}^{+}$ & Clinical strain. \\
\hline 1522 & biofilm-PIA- & $i c a-$ & 20-kDaPS ${ }^{+}$ & Clinical strain \\
\hline 1510 & biofilm ${ }^{+} P I A^{-}$ & $i \mathrm{ca}^{+}$ & 20-kDaPS- & Clinical strain \\
\hline 1505 & biofilmPIA- & ica- & 20-kDaPS- & Clinical strain \\
\hline
\end{tabular}

\section{Methods}

\section{Bacterial strains}

Two reference S. epidermidis strains, ATCC35983 (RP12) and ATCC35984 (RP62A) were used in the present study. Biofilm-producing, PIA-positive S. epidermidis strains 1457, 9142, 8400, and isogenic biofilmnegative, PIA-negative transposon mutants 1457-M10, M22, M23, M24 and 8400-M10 with Tn917 insertion in the icaADBC operon have been described. In mutants 1457-M10 and M24, Tn917 inserted in icaA whereas in M22 and M23 the transposon inserted in icaC $[6,7,31,42,63]$. The transposon was oriented in the same transcriptional direction as the icaADBC operon in all mutants except for M24 in which the transposon inserted in the opposite direction. Also, biofilm-negative, PIA-negative S. epidermidis strains 5179 and 1585 as well as biofilm-positive, PIA-negative variant 5179-R1 were used $[7,64,65]$ (see also Table 3 ).

Seventy-five clinical CoNS isolates from blood cultures and central venous catheter tips collected in the Clinical Laboratory of General University Hospital of Patras, Greece, were used in the present study $(50 \mathrm{~S}$. epidermidis, 12 S. haemolyticus, 9 S. hominis, 1 S. cohnii, 1 S. xylosus, $1 \mathrm{~S}$. capitis, $1 \mathrm{~S}$. lugdunensis). Clinical strains were identified at the species level (API Staph ID 32 cards and automated VITEK system, BioMerieux) and tested for the presence of $i c a A$, icaD1, icaD2, icaC by PCR [6668]. Ability of clinical strains for biofilm formation was assessed quantitatively on microtiter plates, as previously described $[7,69,70]$.

\section{Antisera}

Specific PIA antiserum raised in rabbits against purified polysaccharide I of PIA and specific 20-kDaPS antiserum raised in rabbits against purified $20-\mathrm{kDaPS}$ has been previously described $[4,19,70]$.

\section{Specific antigen detection by immunofluorescence}

Detection of 20-kDaPS and PIA by immunofluorescence was performed, as previously described $[7,70]$. Briefly, overnight cultures of $S$. epidermidis strains in TSB were diluted 1:100 in $2 \mathrm{~mL}$ fresh medium and incubated for $18 \mathrm{~h}$ at $37^{\circ}$ $\mathrm{C}$ with shaking. After brief vortex, bacterial suspensions were adjusted to approximate absorbance 5780.2 (Spectrophotometer, Novaspec Plus) and aliquots (10 $\mu \mathrm{L}$ per well) were applied to immunofluorescence slides (CA Hendley Essex Ltd, Essex, United Kingdom). Slide preparations were air-dried, fixed with cold acetone and stored at $4{ }^{\circ} \mathrm{C}$ until use. Aliquots ( $20 \mu \mathrm{L}$ per field) PIA or $20-\mathrm{kDaPS}$ antisera diluted 1:50 in PBS were applied to slides which were incubated for $30 \mathrm{~min}$ at $37^{\circ} \mathrm{C}$. After washing three times with PBS, $10 \mu \mathrm{L}$ of fluorescein-conjugated anti-rabbit immunoglobulin G (Sigma, UK) diluted 1:80 in phosphate buffered saline were applied, and slides were incubated for $30 \mathrm{~min}$ at $37^{\circ} \mathrm{C}$. After washing, they were mounted using Vectashield and viewed with a Zeiss Axiolmager fluorescence microscope fitted with an AxioCam MR3 camera.

\section{Specific antigen detection by ELISA}

ELISA for polysaccharide detection was performed as previously described [17]. Briefly, antigens, bacterial cells 
or polysaccharide, were applied on a 96-well flat bottom high binding ELISA plate (Greiner) and incubated overnight at $4^{\circ} \mathrm{C}$. Afterwards, plates were blocked by BSA and incubated with $20-\mathrm{kDaPS}$ or PIA antisera for $1 \mathrm{~h}$ at $37^{\circ} \mathrm{C}$. Peroxidase $\mathrm{H}$-conjugated goat anti-rabbit IgG (Sigma Chemical Company, St Louis, MO, USA), diluted 1:2,000 was added for $1 \mathrm{~h}$. Color was developed by adding $100 \mu \mathrm{L} /$ well SureBlue TMB Microwell Peroxidase Substrate (KPL). After incubation for $15 \mathrm{~min}$ at room temperature in the absence of light, the reaction was terminated with $100 \mu \mathrm{L} /$ well of $1 \mathrm{M} \mathrm{H}_{2} \mathrm{SO}_{4}$ and measured at absorbance ${ }_{450}$. ELISA was also performed, as previously described, on 96-well tissue culture plates (Nunc) with similar results.

\section{PIA isolation}

Isolation of PIA antigen was performed, as previously described [6], with slight modification. Briefly, S. epidermidis 1457 was grown for $22 \mathrm{~h}$ at $37^{\circ} \mathrm{C}$ with shaking at $100 \mathrm{rpm} / \mathrm{min}$ in $900 \mathrm{~mL}$ of TSBdia, prepared by dialysis of $100 \mathrm{~mL}$ of 10-fold-concentrated TSB against $900 \mathrm{~mL}$ of water. Bacterial cells were collected by centrifugation and were suspended in $20 \mathrm{~mL}$ of PBS. The antigen was extracted by sonicating cells four times for $30 \mathrm{sec}$ on ice (Branson Digital Sonifier). Cells were removed by centrifugation at $6,000 \mathrm{rpm}$ for $30 \mathrm{~min}$ at $4^{\circ} \mathrm{C}$, and extracts were clarified by centrifugation for $60 \mathrm{~min}$ at $12,000 \mathrm{rpm}$. The extracts $(20 \mathrm{~mL})$ were filter sterilized, dialyzed against $50 \mathrm{mM}$ Tris- $\mathrm{HCl}, \mathrm{pH} 7.5$, overnight, concentrated by using Centriprep 10 (Amicon, Witten), applied to PD10 Q-Sepharose column (Sigma) equilibrated with $50 \mathrm{mM}$ Tris- $\mathrm{HCl}, \mathrm{pH} 7.5$, and fractions of $1.5 \mathrm{~mL}$ were collected.

\section{Influence of proteinase $\mathrm{K}$, sodium meta-periodate and dispersin $B$ treatments on antigen integrity and biofilm stability}

Overnight cultures of different $S$. epidermidis strains in TSB were diluted 1:100 in $5 \mathrm{~mL}$ fresh TSB and incubated in 6-well flat-bottom tissue culture plates (Nunc) for additional $16-18 \mathrm{~h}$ at $37^{\circ} \mathrm{C}$. Supernatants were removed and biofilms were detached using a cell scraper and suspended in $2 \mathrm{~mL}$ PBS. After brief vortex bacterial suspensions were adjusted to absorbance 578 0.2. Aliquots of bacterial cultures $(200 \mu \mathrm{L})$ were supplemented with 40 $\mu \mathrm{L}$ of $0.2 \mathrm{M}$ sodium meta-periodate (Sigma), $2 \mu \mathrm{L}$ of $100 \mu \mathrm{g} / \mathrm{mL}$ proteinase K (Promega, Madison, WI, USA), $2 \mu \mathrm{L}$ of $1 \mathrm{mg} / \mathrm{mL} \mathrm{DspB}$ and incubated at $4^{\circ} \mathrm{C}$ for $16 \mathrm{~h}$, $37^{\circ} \mathrm{C}$ for $16 \mathrm{~h}$ and $37^{\circ} \mathrm{C}$ for $1 \mathrm{~h}$ and $5 \mathrm{~h}$, respectively. Samples were applied onto immunofluorescence slides at appropriate dilution and immunofluorescence tests performed as described above. For testing the stability of established biofilms, bacteria were grown overnight in 96-well cell tissue culture plates (Nunc) as described above. Medium was removed and PBS containing proteinase $\mathrm{K}(1 \mu \mathrm{g} / \mathrm{mL})$ or $\operatorname{DspB}(10 \mu \mathrm{g} / \mathrm{mL})$ or sodium meta-periodate $(0.04 \mathrm{M})$ was added for $16 \mathrm{~h}$ at $37^{\circ} \mathrm{C}$ and at $4^{\circ} \mathrm{C}$ for sodium meta-periodate. Disruption of biofilm integrity was evaluated by assessment the absorbance at $570 \mathrm{~nm}$.

\section{Absorption of antiserum}

20-kDaPS and PIA antiserum were absorbed, as previously described [7], with slight modification. In brief, overnight cultures of selected strains were diluted 1:100 in TSB and incubated with shaking at $100 \mathrm{rpm}$ for $18 \mathrm{~h}$. Bacteria were harvested, washed two times in PBS and resuspended in PBS (absorbance $578=2$ ). Aliquots of this bacterial preparation $(50 \mu \mathrm{L})$ were incubated with one $\mu \mathrm{L}$ of the respective antiserum diluted in $450 \mu \mathrm{L}$ PBS overnight at $4^{\circ} \mathrm{C}$ on a rotating wheel. Bacterial cells were removed by centrifuging twice at $12,000 \times g$ for $15 \mathrm{~min}$ in a mini-centrifuge and the supernatants were filter sterilized.

\section{Antigen expression upon bacterial culture in chemically defined media}

S. epidermidis strains 1457, 1457-M10, and RP12 were subcultured daily for ten days in the following chemically defined broth media: RPMI1640, RPMI1640 + glutamine, IMDM, (Gibco, Invitrogen Life Science), TSB, TSB w/o dextrose and on blood agar plates. 20-kDaPS and PIA expression was assessed by immunofluorescence on day 1,4 , 7 and 10.

\section{Human monocyte derived macrophages}

Human peripheral blood mononuclear cells were isolated from buffy coats by density centrifugation on Ficoll density gradient (Biochrom AG, Berlin) and incubated for $2 \mathrm{~h}$ in RPMI-1640 medium supplemented with 10\% heat-inactivated FCS (Biochrom AG, Berlin) and $2 \mathrm{mM}$ L-Glutamine (HyClone) in $75 \mathrm{~cm}^{2}$ tissue culture flasks (Sarstedt Inc, Newton, NC, USA) at $37^{\circ} \mathrm{C}$ in a humidified, 5\% $\mathrm{CO}_{2}$ atmosphere. Afterwards, non adherent cells were discarded and adherent cells were collected with a cell scraper. Monocytes were differentiated to macrophages after 7 days culture in RPMI-1640 medium supplemented by Gentamicin, Penicillin-Streptomycin (Gibco, Invitrogen, Grand Island, NY, USA), 10\% heatinactivated human $A B$ serum (Invitrogen, USA), $2 \mathrm{mM}$ L-Glutamine and macrophage colony-stimulating factor (10 ng/mL; Abcam, UK). Experimental work using human blood mononuclear cells carried out after obtaining written informed consent of healthy blood donors and was approved by the University of Patras Bioethics Committee. 


\section{Bacterial endocytosis}

In order to assess the impact of 20-kDaPS on S. epidermidis endocytosis, one hundred microliters of a non-20-kDaPSproducing clinical strain (strain 1505$)\left(2 \times 10^{8}\right.$ bacteria/mL) were incubated at room temperature with increasing concentrations $(0,15,30,60 \mu \mathrm{g} / \mathrm{mL})$ of $20-\mathrm{kDaPS}$. In order to assess the impact of $20-\mathrm{kDaPS}$ antiserum on S. epidermidis endocytosis, $100 \mu \mathrm{L}$ of 20-kDaPS-producing strain ATCC35983 and $100 \mu \mathrm{L}$ of non-20-kDaPS-producing clinical strain $\left(2 \times 10^{8}\right.$ bacteria/mL) were incubated at room temperature with $\mathrm{PBS}$, preimmune antiserum and 20$\mathrm{kDaPS}$ antiserum for one $\mathrm{h}$. Afterwards, bacterial suspensions were centrifuged at $12000 \times g$ for ten minutes and further washed with PBS. This procedure was repeated three times. Finally, bacteria were resuspended in PBS at final concentration of $2 \times 10^{7}$ bacteria/mL. Two hundred thousand $\left(2 \times 10^{5}\right)$ macrophages in $0.5 \mathrm{~mL}$ RPMI1640 were incubated with $2 \times 10^{6}$ bacteria preincubated with 20 $\mathrm{kDaPS}$ in different concentrations, preimmune antiserum, $20-\mathrm{kDaPS}$ antiserum or PBS at $37^{\circ} \mathrm{C}$ for one h. Then, $10 \mu \mathrm{L}$ lysostaphin $(1 \mathrm{mg} / \mathrm{mL})$ was added for $15 \mathrm{~min}$ and cells were washed with PBS. Absence of live extracellular bacteria was confirmed by absence of growth on blood agar. Cells were lysed by $0.1 \%$ Triton X-100 and viable intracellular bacteria were counted by plating serial dilutions of the lysates on blood agar plates. Experiments were performed at least five times in triplicate using macrophages from different donors.

\section{Statistical analysis}

Statistical analysis was performed using SPSS 17 statistical package (SPSS Inc, USA). Differences were evaluated using paired $t$ test.

\begin{abstract}
Authors' contributions
AS carried out experimental work and drafted the manuscript. FK designed and participated in experiments involving analysis of clinical strains. MK participated in experiments for 20-kDaPS isolation and helped to draft the manuscript. LH participated in experiments involving comparison of PIA and 20-kDaPS by immunofluorescence and contributed to design of these experiments. TW participated in experiments involving comparison of PIA and $20-\mathrm{kDaPS}$ by ELISA and contributed to design of these experiments. AD participated in the design of the study. GD contributed to design of phagocytosis experiments. NK contributed to design of phagocytosis experiments, structural elucidation, data interpretation and revised the manuscript. DM designed the study and experimental work involving comparison of PIA and 20-kDaPS, interpreted acquired data and revised the manuscript. EA conceived of the study, participated in its design and interpretation of acquired data and revised the manuscript. All authors read and approved the final manuscript.
\end{abstract}

\section{Acknowledgements}

Part of this work was supported by an ESCMID 2009 Training Fellowship given to AS. Part of this work was presented at the $5^{\text {th }}$ Panhellenic Congress of Clinical Microbiology and Hospital Infections, February 2011 and awarded as the best oral presentation by the Organizing Committee. We thank Dr. Jeffrey B. Kaplan, New Jersey Dental School, Newark, USA, for the kind gift of recombinant DspB.

\section{Author details}

${ }^{1}$ Department of Microbiology, School of Medicine, University of Patras, Patras, Greece. ${ }^{2}$ Medical Microbiology and Infectious Diseases, Institute of Life Science, The College of Medicine, Swansea University, Swansea, UK. 'Laboratory of Biochemistry, Department of Chemistry, University of Patras, Patras, Greece.

Received: 22 October 2011 Accepted: 17 May 2012

Published: 17 May 2012

\section{References}

1. Vuong C, Otto M: Staphylococcus epidermidis infections. Microbes Infect 2002, 4:481-489.

2. Von Eiff C, Peters G, Heilmann C: Pathogenesis of infections due to coagulase-negative staphylococci. Lancet Infect Dis 2002, 2:677-685.

3. Mack D, Davies A, Harris L, Rohde H, Horstkotte M, Knobloch J: Microbial interactions in Staphylococcus epidermidis biofilms. Anal Bioanal Chem 2007, 387:399-408.

4. Mack D, Fischer W, Krokotsch A, Leopold K, Hartmann R, Egge H, Laufs R: The Intercellular Adhesin Involved in Biofilm Accumulation of Staphylococcus epidermidis Is a Linear $\beta-1,6$-Linked Glucosaminoglucan: Purification and Structural Analysis. J Bacteriol 1996, 178:175-183.

5. Mack D, Haeder M, Siemssen N, Laufs R: Association of biofilm production of coagulase-negative staphylococci with expression of a specific polysaccharide intercellular adhesion. J Infect Dis 1996, 174:881-884.

6. Mack D, Nedelmann M, Krokotsch A, Schwarzkopf A, Heesemann J, Laufs R: Characterization of Transposon Mutants of Biofilm-Producing Staphylococcus epidermidis Impaired in the Accumulative Phase of Biofilm Production: Genetic Identification of a Hexosamine-Containing Polysaccharide Intercellular Adhesin. Infect Immun 1994, 62:3244-3254.

7. Mack D, Siemssen N, Laufs R: Parallel Induction of Glucose of Adherence and a Polysaccharide Antigen Specific for Plastic-Adherent Staphylococcus epidermidis: Evidence for Functional Relation to Intercellular Adhesion. Infect Immun 1992, 60:2048-2057.

8. Rupp M, Ulphani JS, Fey PD, Mack D: Characterization of Staphylococcus epidermidis Polysaccharide Intercellular Adhesin/Hemagglutinin in the Pathogenesis of Intravascular Catheter-Associated Infection in a Rat Model. Infect Immun 1999, 67:2656-2659.

9. Vuong C, Voyich JM, Fischer ER, Braughton KR, Whitney AR, DeLeon FR, Otto M: Polysaccharide intercellular adhesin (PIA) protects Staphylococcus epidermidis against major components of the human innate immune system. Cell Microbiol 2004, 6:269-275.

10. Kristian SA, Birkenstock TA, Sauder U, Mack D, Götz F, Landmann R: Biofilm formation induces C3a release and protects Staphylococcus epidermidis from IgG and complement deposition and from neutrophil-dependent killing. J Infect Dis 2008, 197:1028-1035.

11. Heilmann C, Schweitzer O, Gerke C, Vanittanakom N, Mack D, Götz F: Molecular basis of intercellular adhesion in the biofilm-forming Staphylococcus epidermidis. Mol Microbiol 1996, 20:1083-1091.

12. Heilmann C, Gerke, Perdreau-Remington F, Gotz F: Characterization of Tn917 insertion mutants of Staphylococcus epidermidis affected in biofilm formation. Infect Immun 1996, 64:277-282.

13. Gerke C, Kraft A, Sußmuth R, Schweitzer O, Gotz F: Characterization of the $\mathrm{N}$-Acetylglucosaminyltransferase Activity Involved in the Biosynthesis of the Staphylococcus epidermidis Polysaccharide Intercellular Adhesin. J Biol Chem 1996, 273:18586-18593.

14. Arvaniti A, Karamanos NK, Dimitracopoulos G, Anastassiou ED: Isolation and Characterization of a Novel 20-kDa Sulfated Polysaccharide from the Extracellular Slime Layer of Staphylococcus epidermidis. Arch Biochem Biophys 1994, 308:432-438.

15. Karamanos NK, Panagiotopoulou HS, Syrokou A, Frangides C, Hjerpe A, Dimitracopoulos G, Anastassiou ED: Identity of macromolecules present in the extracellular slime layer of Staphylococcus epidermidis. Biochimie 1995, 77:217-224.

16. Krevvata MI, Afratis N, Spiliopoulou A, Malavaki CJ, Kolonitsiou F, Anastassiou E, Karamanos NK: A modified protocol for isolation and purity evaluation of a staphylococcal acidic polysaccharide by chromatography and capillary electrophoresis. Biomed Chromatogr 2010, 25:531-534.

17. Kolonitsiou F, Syrokou A, Karamanos NK, Anastassiou ED, Dimitracopoulos G: Immunoreactivity of 80-kDa peptidoglycan and teichoic acid-like 
substance of slime-producing S. epidermidis and specificity of their antibodies studied by an enzyme immunoassay. J Pharm Biomed Anal 2001, 24:429-436.

18. Lamari FN, Anastassiou ED, Kolonitsiou F, Dimitracopoulos G, Karamanos NK: Potential use of solid phase immunoassays in the diagnosis of coagulase-negative staphylococcal infections. J Pharm Biomed Anal 2004, 34:803-810

19. Karamanos NK, Syrokou A, Panagiotopoulou HS, Anastassiou ED Dimitracopoulos G: The Major 20-kDa Polysaccharide of Staphylococcus epidermidis Extracellular Slime and Its Antibodies as Powerful Agents for Detecting Antibodies in Blood Serum and Differentiating among SlimePositive and -Negative S. epidermidis and other Staphylococci species. Arch Bioch Biophys 1997, 342:389-395.

20. Georgakopoulos CG, Exarchou AM, Gartaganis SP, Kolonitsiou F, Anastassiou ED, Dimitracopoulos G, Hjerpe A, Theocharis AD, Karamanos NK: Immunization with Specific Polysaccharide Antigen Reduces Alterations in Corneal Proteoglycans During Experimental Slime-Producing Staphylococcus epidermidis Keratitis. Curr Eye Res 2006, 31:137-146.

21. Georgakopoulos CG, Exarchou AM, Koliopoulos JX, Gartaganis SP, Anastassiou ED, Kolonitsiou F, Lamari F, Karamanos NK, Dimitracopoulos G: Levels of specific antibodies towards the major antigenic determinant of slime-producing Staphylococcus epidermidis determined by an enzyme immunoassay and their protective effect in experimental keratitis. $J$ Pharm Biomed Anal 2002, 29:255-262.

22. Petropoulos IK, Vantzou CV, Lamari FN, Karamanos NK, Anastassiou ED, Pharmakakis NM: Expression of TNF-alpha, IL-1 beta, and IFN-gamma in Staphylococcus epidermidis slime-positive experimental endophthalmitis is closely related to clinical inflammatory scores. Graefes Arch Clin Exp Ophthalmol 2006, 244:1322-1328.

23. Lamari F, Anastassiou ED, Stamokosta E, Photopoulos S, Xanthou M, Dimitracopoulos G, Karamanos NK: Determination of slime-producing Staphylococcus epidermidis specific antibodies in human immunoglobulin preparations and blood sera by an enzyme immunoassay. Correlation of antibody titers with opsonic activity and application to preterm neonates. J Pharm Biomed Anal 2000, 23:363-374.

24. Krevvata MI, Spiliopoulou A, Anastassiou ED, Karamanos NK, Kolonitsiou F: Adherence of Staphylococcus epidermidis to human endothelial cells is associated to a polysaccharidic component of its extracellular mucous layer. Connect Tissue Res 2011, 52:183-189.

25. Tojo M, Yamashita N, Goldmann DA, Pier GB: Isolation and characterization of a capsular polysaccharide adhesin from Staphylococcus epidermidis. J Infect Dis 1998, 157:713-722.

26. McKenney D, Hubner J, Muller E, Wang Y, Goldmann D, Pier G: The ica Locus of Staphylococcus epidermidis Encodes Production of the Capsular Polysaccharide/Adhesin. Infect Immun 1998, 66:4711-4720.

27. McKenney D, Pouliot K, Wang Y, Murphy V, Urlich M, Doring G, Lee JC, Goldmann DA, Pier GB: Vaccine potential of poly-1-6- $\beta-D-N-$ succinylglucosamine, an immunoprotective surface of Staphylococcus aureus and Staphylococcus epidermidis. J Biotechnol 2000, 83:37-44.

28. Maira-Litran T, Kropec A, Abeygunawardana C, Joyce J, Mark G 3rd Goldmann DA, Pier GB: Immunochemical Properties of the Staphylococcal Poly-N-Acetylglucosamine Surface Polysaccharide. Infect Immun 2002, 70:4433-4440.

29. Christensen GD, Barker LP, Mawhinney TP, Baddour LM, Simpson WA: Identification of an Antigenic Marker of Slime Production for Staphylococcus epidermidis. Infect Immun 1990, 58:2906-2911.

30. Baldassarri L, Donnelli G, Gelosia A, Voglino MC, Simpson AW, Christensen GD: Purification and Characterization of the Staphylococcal SlimeAssociated Antigen and Its Occurrence among Staphylococcus epidermidis Clinical Isolates. Infect Immun 1996, 64:3410-3415.

31. Gotz F: Staphylococcus and biofilms. Mol Microbiol 2002, 43:1367-1378.

32. Mack D, Riedewald J, Rohde H, Magnus T, Feucht HH, Elsner H-A, Laufs R, Rupp ME: Essential Functional Role of the Polysaccharide Intercellular Adhesin of Staphylococcus epidermidis in Hemagglutination. Infect Immun 1999, 67:1004-1008.

33. Maira-Litran T, Kropec A, Goldmann D, Pier GB: Biologic properties and vaccine potential of the staphylococcal poly- $\mathrm{N}$-acetyl glucosamine surface polysaccharide. Vaccine 2004, 22:872-879.

34. Rohde H, Frankenberger S, Zähringer U, Mack D: Structure, function and contribution of polysaccharide intercellular adhesin (PIA) to
Staphylococcus epidermidis biofilm formation and pathogenesis of biomaterial-associated infections. Eur J Cell Biol 2010, 89:103-111.

35. Sadovskaya I, Vinogradov E, Flahaut S, Kogan G, Jabbouri S: Extracellular Carbohydrate-Containing Polymers of a Model Biofilm-Producing Strain, Staphylococcus epidermidis RP62A. Infect Immun 2005, 73:3007-3017.

36. Mack D, Davies AP, Harris LG, Knobloch JK-M, Rohde H: Staphylococcus epidermidis Biofilms: Functional Molecules, Relation to Virulence, and Vaccine Potential. Top Curr Chem 2009, 288:57-182.

37. Rohde H, Knobloch JK, Horstkotte MA, Mack D: Correlation of biofilm expression types of Staphylococcus epidermidis with polysaccharide intercellular adhesin synthesis: evidence for involvement of icaADBC genotype-independent factors. Med Microbiol Immunol 2001, 190:105-112.

38. Kaplan JB, Ragunath C, Velliyagounder K, Fine DH, Ramasubbu N: Enzymatic Detachment of Staphylococcus epidermidis Biofilms. Antimicrob Agents Chemother 2004, 48:2633-2636.

39. Rohde H, Burandt EC, Siemssen N, Frommelt L, Burdelski C, Wurster S, Scherpe S, Davies AP, Harris LG, Horstkotte MA, Knobloch JK-M, Ragunath C, Kaplan JB, Mack D: Polysaccharide intercellular adhesin or protein factors in biofilm accumulation of Staphylococcus epidermidis and Staphylococcus aureus isolated from prosthetic hip and knee joint infections. Biomaterials 2007, 28:1711-1720.

40. Chokr A, Watier D, Eleaume H, Pangon B, Ghnassia J-C, Mack D, Jabbouri S: Correlation between biofilm formation and production of polysaccharide intercellular adhesin in clinical isolates of coagulase-negative staphylococci. Int J Med Microbiol 2006, 296:381-388.

41. Rohde H, Kalitzky M, Kroger N, Scherpe S, Horstkotte MA, Knobloch JK, Zander AR, Mack D: Detection of Virulence-Associated Genes Not Useful for Discriminating between Invasive and Commensal Staphylococcus epidermidis Strains from a Bone Marrow Transplant Unit. J Clin Microbiol 2004, 42:5614-5619.

42. Ziebuhr W, Heilmann C, Gotz F, Meyer P, Wilms K, Straube E, Hacker J: Detection of the intercellular adhesion gene cluster (ica) and phase variation in Staphylococcus epidermidis blood culture strains and mucosal isolates. Infect Immun 1997, 65:890-896.

43. Otto M: Staphylococcus epidermidis - the 'accidental' pathogen. Nat Rev Microbiol 2009, 7:555-567.

44. Dobinsky S, Bartscht K, Mack D: Influence of Tn917 Insertion on Transcription of the icaADBC Operon in Six Biofilm-Negative Transposon Mutants of Staphylococcus epidermidis. Plasmid 2002, 47:10-17.

45. DeLoid GM, Sulahian TH, Imrich A, Kobzik L: Heterogeneity in Macrophage Phagocytosis of Staphylococcus aureus Strains: High-Throughput Scanning Cytometry-Based Analysis. PLoS One 2009, 4:e6209.

46. Laine RA: The Information-Storing Potential of the Sugar Code. In Glycosciences: Status and Perspectives. Edited by Gabius HJ, Gabius S. Weinheim: Wiley-VCH Verlag GmbH \& Co KGaA; 2002:7.

47. Aderem A, Underhill D: Mechanisms of phagocytosis in macrophages. Ann Rev Immunol 1999, 17:593-623.

48. Allen LA, Schlesinger LS, Kang B: Virulent strains of Helicobacter pylori demonstrate delayed phagocytosis and stimulate homotypic phagosome fusion in macrophages. J Exp Med 2000, 191:115-128.

49. Ernst JD: Bacterial inhibition of phagocytosis. Cell Microbiol 2000, 2:379-386.

50. Pruimboom IM, Rimler RB, Ackermann MR, Brogden KA: Capsular hyaluronic acid-mediated adhesion of Pasteurella multocida to turkey air sac macrophages. Avian Dis 1996, 40:887-893.

51. Pruimboom IM, Rimler RB, Ackermann MR: Enhanced Adhesion of Pasteurella multocida to Cultured Turkey Peripheral Blood Monocytes. Infect Immun 1999, 67:1292-1296.

52. Albanyan EA, Vallejo JG, Smith CW, Edwards MS: Nonopsonic Binding of Type III Group B Streptococci to Human Neutrophils Induces Interleukin8 Release Mediated by the p38 Mitogen-Activated Protein Kinase Pathway. Infect Immun 2000, 68:2053-2060.

53. Rennermalm A, Nilsson M, Flock J-l: The fibrinogen Binding Protein Of S. epidermidis is a Target for Opsonic Antibodies. Infect Immun 2004 72:3081-3083.

54. Weisman LE, Fischer GW, Thackray HM, Johnson KE, Schuman RF, Mandy GT, Stratton BE, Adams KM, Kramer WG, Mond JJ: Safety and pharmacokinetics of a chimerized anti-lipoteichoic acid monoclonal antibody in healthy adults. Int Immunopharmacol 2009, 9:639-644. 
55. Broekhuizen CA, de Boer L, Schipper K, Jones CD, Quadir S, Feldman RG, Vandenbroucke-Grauls CM, Zaat SA: The influence of antibodies on Staphylococcus epidermidis adherence to polyvinylpyrrolidone-coated silicone elastomer in experimental biomaterial-associated infection in mice. Biomaterials 2009, 30:6444-6450.

56. Harro JM, Peters BM, O'May GA, Archer N, Kerns P, Prabhakara R, Shirtliff ME: Vaccine development in Staphylococcus aureus: taking the biofilm phenotype into consideration. FEMS Immunol Med Microbiol 2010, 59:306-323.

57. McKenney D, Pouliot KL, Wang Y, Murthy V, Ulrich M, Döring G, Lee JC, Goldmann DA, Pier GB: Broadly protective vaccine for Staphylococcus aureus based on an in vivo expressed antigen. Science 1999, 284:1523-1527.

58. Maira-Litran T, Kropec A, Goldmann DA, Pier GB: Comparative opsonic and protective activities of Staphylococcus aureus conjugate vaccines containing native or deacetylated staphylococcal poly-N-acetyl-beta-(1-6)glucosamine. Infect Immun 2005, 73:6752-6762

59. Perez MM, Prenafeta A, Valle J, Penadés J, Rota C, Solano C, Marco J, Grilló MJ, Lasa I, Irache JM, Maira-Litran T, Jiménez-Barbero J, Costa L, Pier GB, de Andrés D, Amorena B: Protection from Staphylococcus aureus mastitis associated with poly-N-acetyl beta-1,6 glucosamine specific antibody production using biofilm-embedded bacteria. Vaccine 2009, 27:2379-2386.

60. Gening M, Maira-Litran T, Kropec A, Skurnik D, Grout M, Tsvetkov YE, Nifantiev NE, Pier GB: Synthetic beta-(1,6)-linked N-acetylated and nonacetylated oligoglucosamines to produce conjugate vaccines for bacterial pathogens. Infect Immun 2010, 78:764-772.

61. Spellberg B, Daum R: A new view on development of a Staphylococcus aureus vaccine. Hum Vaccin 2010, 6:857-859.

62. Ohlsen $\mathrm{K}$, Lorenz U: Immunotherapeutic strategies to combat staphylococcal infections. Int J Med Microbiol 2010, 300:402-410.

63. Mack D, Rohde H, Dobinsky S, Riedewald J, Nedelmann M, Knobloch JK-M, Elsner $\mathrm{H}-\mathrm{A}$, Feucht $\mathrm{HH}$ : Identification of three essential regulatory gene loci governing expression of the Staphylococcus epidermidis polysaccharide intercellular adhesion and biofilm formation. Infect Immun 2000, 68:3799-3807.

64. Rohde H, Burdelski C, Bartscht K, Hussain M, Buck F, Horstkotte MA, Knobloch JK-M, Helimann C, Herrmann M, Mack D: Induction of Staphylococcus epidermidis biofilm formation via proteolytic processing of the accumulation-associated protein by staphylococcal and host proteases. Mol Microbiol 2005, 55:1883-1895.

65. Christner M, Franke G, Schommer N, Wendt U, Wegert K, Pehle P, Kroll G, Schulze C, Buck F, Mack D, Aepfelbacher M, Rohde H: The giant extracellular matrix binding protein of Staphylococcus epidermidis mediates biofilm accumulation and attachment to fibronectin. $\mathrm{Mol}$ Microbiol 2010, 75:187-207.

66. Arciola CR, Baldassarri L, Montanaro: Presence of icaA and icaD Genes and Slime Production in a Collection of Staphylococcal Strains from Catheter-Associated Infections. J Clin Microbiol 2001, 39:2151-2156.

67. De Silva GDI, Kantzanou M, Justice A, Massey RC, Wilkinson AR, Day NPJ, Peacock SJ: The ica operon and biofilm production in coagulase-negative staphylococci associated with carriage and disease in a neonatal intensive care unit. J Clin Microbiol 2002, 40:382-388.

68. Ziebuhr W, Krimmer V, Rachid S, Lobner I, Gotz F, Hacker J: A novel mechanism of phase variation of virulence in Staphylococcus epidermidis: evidence for control of the polysaccharide intercellular adhesin synthesis by alternating insertion and excision of the insertion sequence element IS256. Mol Microbiol 1999, 32:345-350.

69. Nilsdotter-Augustinsson A, Koskela A, Öhman L, Söderquist B: Characterization of coagulase-negative staphylococci isolated from patients with infected hip prostheses: use of phenotypic and genotypic analyses, including tests for the presence of the ica operon. Eur J Clin Microbiol Infect Dis 2007, 26:255265.

70. Mack D, Bartscht K, Fischer C, Rohde H, De Grahl C, Dobinsky S, Horstkotte MA, Kiel K, Knobloch JK-M: Genetic and Biochemical Analysis of Staphylococcus epidermidis Biofilm Accumulation. Meth Enzymol 2001, 336:215-239.

\section{Submit your next manuscript to BioMed Central and take full advantage of:}

- Convenient online submission

- Thorough peer review

- No space constraints or color figure charges

- Immediate publication on acceptance

- Inclusion in PubMed, CAS, Scopus and Google Scholar

- Research which is freely available for redistribution 